\title{
A Review of Influencing Factors for Selection of Engineering Pathway for Women - A Case Study of Females Studying Engineering at Waikato Institute of Technology (Wintec), New Zealand
}

\author{
Maryam Moridnejad ${ }^{1}$, Josy Cooper ${ }^{l}$, Wendy H Fox-Turnbull ${ }^{2}$ and Sarla Kumari ${ }^{l}$ \\ ${ }^{I}$ Centre for Engineering and Industrial Design (CEID), Waikato Institute of Technology (Wintec), New Zealand; \\ ${ }^{2}$ Division of Education, University of Waikato, New Zealand \\ *Corresponding author: maryam.moridnejad@ wintec.ac.nz
}

\begin{abstract}
Females are underrepresented in engineering cohorts in New Zealand. The lack of female participation in engineering fields at the tertiary education level has been a barrier for diversity and equality in both the industry and academic professions. A recent study by Docherty et al. [11] noted girls coming to engineering at Canterbury University, New Zealand are more likely to be from a single sex school and this phenomenon can be due to cultural reasons. They identified that future work is needed to look at the cultural changes in New Zealand which could potentially mitigate the gender bias.
\end{abstract}

However, we first need to identify a range of contributing factors (including cultural issues) for the lack of diversity in engineering schools in New Zealand. By identifying these factors, we can then propose and implement necessary remediation actions to address the lack of female participation in engineering. Common influencing factors for female participation in STEM and selection of engineering pathways were found during a review of literature and included parental and teacher influences, self-efficacy, perception and attitude, gender stereotypes, and peer and media influences. We believe that New Zealand context in terms of how it influences female study and career pathway to engineering has not been well studied and documented to date. The objective of this research is to identify the main factors and cultural issues that contribute to low female participation in engineering studies in New Zealand.

We carried out individual and focus group interviews on both domestic and international female students at Wintec enrolled in the Diploma, Bachelor of Engineering Technology and Graduate Diploma programmes in Civil Engineering. The interviews helped us to understand our students' perspectives around the factors that influenced their study decisions. We used the collected data to identify patterns and generate themes.
In the New Zealand context, we found, barriers to selection of engineering pathway for females include the school system; lack of career and subject choice guidance available to students at school, lack of promotion of the profession, and society's perception of engineers as being masculine - "a tradie working in a workshop". For our international students' participants, it appears that the school system in their country directed them (regardless of gender) to maths and engineering study pathways if they showed talent in these areas and engineering is a highly regarded profession.

Keywords: Influencing factors, Female, Engineering, diversity, Wintec, New Zealand

\section{INTRODUCTION}

Females are underrepresented in engineering cohorts in New Zealand. The lack of female participation in engineering fields at the tertiary education level has been a barrier for diversity and equality in both the industry and academic professions. Docherty et al. [11] carried out research looking at the numbers of female students enrolled in the College of Engineering at the University of Canterbury, New Zealand, between the years of 2005 and 2017. They found that there was a trend towards female students from single sex schools being more represented in Engineering compared to female students from coeducational schools. Their paper discussed further the potential of cultural reasons relating to this phenomenon, noting that future work should look at cultural changes in New Zealand which could potentially mitigate the gender bias. However, as Docherty et al. [11] also confirmed, we first need to identify a range of contributing factors (including cultural issues) for the lack of diversity in engineering schools in New Zealand. By identifying these factors, we can then propose and implement necessary 
remedial actions to address the lack of female participation in engineering.

Influencing factors/barriers for female participation in STEM and selection of engineering pathway were found during a review of literature as following:

- Parental Influence;

- Teacher Influence;

- Self-Efficacy, Perception and Attitude;

- Gender Stereotypes;

- Peer Influence;

- Media Influence.

These factors are discussed comprehensively in a multitude of international contexts; however, different countries show different rates of female participation in engineering fields [14]. We believe that New Zealand context in terms of the cultural factors and how it influences female study and career pathways has not been well studied and documented to date. The objective of this research is to identify the main factors and cultural issues that contribute to low female participation in engineering studies in New Zealand.

To identify the influential factors, we interviewed current female students enrolled in the Diploma, Bachelor of Engineering Technology and Graduate Diploma programmes in Civil Engineering at the Waikato region's technical institute, Wintec. Focus group and individual interviews have enabled insight into female students' perspectives of influences in their study decisions.

\section{BACKGROUND}

Researchers such as Mozahem et al. [17] have sought to understand the influential factors leading to female choices in the areas of STEM for a long time. There appears to be collective agreement that these factors can be grouped into categories relating to family, friends, community, teachers, self-confidence and perception, gender stereotypes and media influence. Each of which are discussed below.

\subsection{Parental Influence}

Parents unconsciously expose their young boys more to mathematical and scientific concepts than their girls and as a result, there is a difference in their understanding when they enter school. Levine et al. [16] found that, in early childhood, the mathematical conversation that parents have with their young children has an important effect in developing their understanding about the maths concepts. In a study that Crowley et al. [8] conducted at a California children's museum, they observed that parents provided at least one scientific explanation in $29 \%$ of their conversations with their boys as opposed to $9 \%$ in their interactions with their girls. However, this does not mean than boys initiated these scientific conversations significantly more than girls (78\% and $74 \%$, respectively). The difference in providing explanation was mostly seen in father-child interactions.

Mothers' gender related beliefs and what they expect from their adolescent children, has a large impact on their children's career choice in young adulthood [6]. Mothers' gender related career expectations from their girls and boys has been shown to be significantly correlated with their children's gender related career expectations [21].

\subsection{Teacher Influence}

Teachers of young children can unconsciously communicate their own believes and attitudes about science and maths to their students. Studies showed that higher maths anxiety in female teachers was correlated with the lower score in maths in female students and made the female students believe in traditional gender abilities that boys are better than girls. This pattern was not seen in male students. The more girls believed in this gender-type abilities, the lower their maths score was at the end of the school year. Previous studies by Perry and Bussey [20] showed that young children model the behaviours of the same-sex adults and this explains why female students are most negatively influenced by their female teacher with maths anxiety.

Psychologists have shown that implicit behaviour (behaviour that is held in the subconscious mind and is not clear for a person in conscious awareness) can have a significant impact on peoples' behaviour. The perception of males being better at STEM subjects by teachers is passed on to their students subconsciously [20]. This implicit attitude can strongly impact on how teachers interact with their female and male students. A study by Dickhäuser and Meyer [10] showed that on average, teachers of 8-12 years old, believe that boys have higher math ability than girls, even though they perform almost the same. Teachers often relate the mathematical success of female students to high efforts whereas for male students, they relate their success to high ability, and they assume that boys have higher logical thinking abilities. Teachers' negative evaluation about girls' abilities in math can even overrule their actual good performance and become their beliefs.

\subsection{Self-Efficacy, Perception and Attitude}

The perception of people about their own ability to succeed (self-efficacy) is a very important contributor to their success in their studies. If girls do not think positively about their own mathematical ability, it will affect their later achievement $[15,18]$. Self-efficacy in boys is related 
to their actual performance in math but for girls even if they perform well, they might still believe that they are not good enough [10]. Parents, on average, believe that boys have more maths capability than girls [26].

Parental beliefs are aligned with teachers' perspectives about girls having less mathematical capability without any actual differences in girls' and boys' performances. Studies showed that mothers and teachers' beliefs about children's ability had strongly influenced children's perception about their own abilities. Parents beliefs about their children's capabilities have a significant effect on how they perform and what they do [21]. Like teachers, a mother's beliefs can be the results of her own experiences and socialisation and are unconsciously communicated to her daughter. These influential factors create a girl's perception about her mathematical abilities which has nothing to do with her actual performance and becomes her reality only because of her gender. Adolescent girls' self-efficacy in their career in STEM, has strongly correlated with their mothers' expectations for their success. Mothers' perception of their Grade 7 (10-11 years) children success in STEM, has proved to be correlated to their adult self-efficacy in their career in the field of STEM at the age of 20 years old [5]. The difference in selfefficacy between men and women is significant when adolescence is over. Men at the age of 19-20 years old, have substantially higher self-efficacy in STEM fields than women [6].

In adolescence, how students think about their academic ability and their intelligence defines their mindset and plays an important role in their attitudes towards STEM [21]. Adults either have a fixed mindset which they believe that their academic ability is fixed and cannot be improved or they have a growth mindset where they believe their academic ability develops with practice and time [13]. If students have a fixed mindset, when they face a challenge in their studies, they lose their confidence and productiveness and they relate the problem to their lack of natural abilities. For example, they believe if they are gifted in math, they will understand all the new concepts in math without facing problems. In contrast, students with growth mindset, when they find a challenge in math, they persist to overcome the problem with putting in more effort [21]. A study by Blackwell et al. [4] showed that a growth mindset of intelligence can be taught to students and holding a growth mindset, can stop the decline in math performance in middle school students.

\subsection{Gender Stereotypes}

Students in elementary school identify science-related professions as masculine [1]. Boys as young as 7 years old, believe that they are better in math than girls, while girls believe that they are equally good at math with boys.
Around 10 years old, girls start to think that boys are better than them in maths [18]. Adolescence also holds gender stereotypes about STEM. During adolescence, boys in their explicit statements, believe they are equally good with girls at maths while girls still believe that boys are better at math than them [21]. The change in boys' opinion can be the result of what they believe is socially acceptable than a real change in their beliefs. Research shows that people may hold implicit (unconscious) beliefs about stereotypes that does not align with explicit beliefs of gender equality that is socially acceptable [9]. Even though in recent times, there are a lot of explicit statements about the equality of boys and girls at maths, still for many people the unconscious beliefs about the male superiority remain unchanged and these effects the girl's performance [21].

\subsection{Peer and Media Influences}

Peer attitude is also another source of influence in children's interest in math and science. As expected, if peers have a positive attitude about science and math, this would have a positive influence on children [22] and this can impact on their career choice in science in the future [23] in both girls and boys. The peer's impact toward science grows stronger through middle school and reaches to its highest point of influence during high school [25].

Media has also potentially influenced girls' attitudes and beliefs about math and science by showing that science is a masculine area [21]. The media and public have long perceived engineering as a male dominated profession [2].

Based on the previous discussions, it becomes clear that there are a lot of reasons why women choose STEM related majors less than men, and those women who graduate from STEM related fields are less likely to work in this area than men. The gender wage gap is significantly smaller in STEM fields than other non-STEM majors. Encouraging more women in STEM careers could go some way to decreasing the gender pay gap in society, as STEM jobs for women pay on average $33 \%$ more than other fields [3].

A study by Mozahem et al. [17] showed that the environment around females when they decide on careers, including friends, financial considerations, family, etc, acts strongly to influence their career decisions. If they had a strong "inner environment" being supportive parents and close friends, then they were more likely to choose and persist in engineering. However, when talented women do not choose to work in STEM related careers, the whole society will eventually pay the price. Scientist women diversify the topics investigated in their fields and the new research areas will be beneficial for the whole community. In addition, having a highly skilled workforce in STEM 
related fields will be very important for country's economic growth and development [21].

\section{METHODOLOGY}

\subsection{Conceptual Framework}

This social research has been carried out using a subjective approach as per Cohen et al. [7] with an interpretive paradigm. Interpretive social science paradigm is a major theoretical paradigm used widely, concerned with understanding through feelings and world views [19]. This paradigm aims to understand the world of human experience by the subjective experiences of individuals. The use of this paradigm has allowed us to develop questions for the interviews and focus group to a format that permitted later examination of how the participants have interacted with their environment.

We carried out systematic analysis of their actions through the direct and detailed observation of the participants during the interviews and focus groups to interpret how they have created and maintained their social worlds (Neuman, 2000). Emergent themes, including gender, access to advice, national culture and fixed vs. growth mindset, were identified from the discussions based on outcomes from the video recordings and transcripts. The focus group was a particularly useful method that allowed interactions between participants from different backgrounds to discuss and explore their understanding of their social worlds and how these led them to become engineering students.

\subsection{Interviews and Focus Group}

The question that was investigated in this research is "What are the main factors and cultural issues that contribute to low female participation in engineering studies in New Zealand?". To identify these factors, a focus group, individual interviews, and a small questionnaire were used. The use of this qualitative data provided descriptions of various influences leading to female career choices in Engineering.

Five female international students currently enrolled in the Diploma, Bachelor of Engineering Technology and Graduate Diploma programmes in Civil Engineering at Wintec were interviewed individually. This data was analysed to determine questions and discussion points for a focus group which, also comprised of five female domestic students currently enrolled at Wintec in the same programmes as listed previously. It is worth noting that all the students (except for one domestic student) were adult learners - i.e. they had not come to study with Wintec directly after school, and first pursued other studies or worked.
The interviews aimed to gain insight into participants' perspectives around the factors that influenced their study decisions. The interview questions were based on information provided by the questionnaire that was given to participants' before attending the interview.

\subsection{Questionnaire}

The questionnaire was supplied prior to the interviews and focus groups, to give participants time to think about the questions and their answers in advance, giving them the best opportunity to provide thoughtful, honest, and personal response. An open-ended questionnaire was designed. As Cohen et al. [7] mention, the advantages of having an open-ended questionnaire is that it can be a window of opportunity for the respondents to shed light on an issue, to write their opinions in their own terms with their own words without limitations of pre-defined categories of response and is especially suitable for investigating complex issues similar to what we are investigating in our research.

If poorly constructed, open-ended questionnaires can result in unnecessary and irrelevant information being collected, especially in the case where respondents do not know what type of information is required or they have problems with articulating their thoughts [7]. In this research, prompts in some of the questions provided support for the respondents assisting them to articulate responses avoiding the gathering of irrelevant information and enabling the interviewers to delve into more in-depth information during questioning. It also provides guidance to any participants that have difficulty understanding the purpose of a question.

The questions asked included background questions to cover off age, marital status, nationality, high school location, and parents' jobs. The questions then delved into detail to gauge the participants personal viewpoint and values by asking the following:

- Did your parents support you when you decided to study engineering? What was their reaction? What did the support of your parents look like? [examples - financial, took you to talk to an engineer, took you to a talk about engineering as a career etc].

- Did your high school teachers provide support for selection of engineering majors? What was their opinion about science, maths, and engineering? How did the support at school look like? e.g. did your teachers talk to you early on about pathways in maths and science [engineering], did they bring in outside speakers to talk at school? Introduce role models? Were there any barriers such as lack 
of [good] maths/science teachers, timetabling, funding at your school?

- How about your friends and other family members? How did they react when you chose engineering? Did their reaction affect/influence your decision to study engineering?

- What are the reasons you choose engineering? E.g. financial, status, interest in how things and how they work, interest in how the design of the world around us affects people?

- Are you happy so far with your qualification? And why? If you could change one thing about the support or content or structure of your qualification, what would you suggest and why?

- Did you have any role models? Who is/was your role model and why?

- Would you describe yourself as an ambitious and hardworking person? And why? Where do you think your motivations come from?

- How do you see your future? What kind of leadership role can you imagine yourself doing in future?

- Why do you think girls are not very attracted to engineering in New Zealand? What factors do you think are contributing in their lack of interest in the subject?

- What do you think needs to be done to attract more girls to engineering?

- Have there been any instances where you have felt like dropping out/leaving engineering study?

- What were those instances and why? What made you stay?

At the beginning of each interview, another questionnaire was supplied to participants intended to indicate whether the participants had fixed or growth mindsets. These questions were sourced from a book by Dweck [12]. Interviews were video recorded to recall data if needed. Data was saved and organized for analysis. Emerging patterns and themes were identified and are presented in this paper. Further analysis and results that not reported in this paper are expected.

\subsection{Limitations}

There was an existing relationship between interviewers and interviewees as the first two authors were lecturers in the programmes taken by the participants. While this can be viewed as a key factor to generate trust and facilitate genuine authentic conversation about the talking points, there may have also been some power distance between interviewers and interviewees. The interviewees, possibly the international students, might feel that negative responses to questions would alter the interviewer's perception of them and affect their future grades. All efforts were made to assure participants that participation was voluntary, and that everything discussed was to be kept private.

\section{RESULTS}

Some key findings of this study have included interesting differences and similarities between our international and domestic female participants. Results are organised according to key career influencers identified in the literature and compared/contrasted findings from the international participants with the domestic focus group responses.

\subsection{Parental influence}

For international participants, strong parental influence was prevalent across all interview subjects. The parental support included full financial support as well as emotional support.

For domestic participants varied parental influence was found. The parental support was more 'generic' with no specific parental guidance towards selection of engineering as a study pathway.

Some of the responses received by our domestic participants from their parents, to their selection of engineering study, are quoted below:

\section{"Good Luck!"}

"Oh wow, that's cool."

"Mum thought it was a good idea, she researched a lot of career options with me."

"Oooo, nice!"

"My parents said we will support you whatever you want to do, there was no focus on what I was going to do, other than to do something."

"Just do what you want to do."

"My parents didn't think that I suited engineering because my sister who is an engineer is more of a tomboy and I am not."

\subsection{Teacher and School Influence}

The largest barrier for domestic participants appeared to be the school system and lack of career guidance. The international participant journey seemed to be facilitated by their school systems. While for domestic participants career advice was given either late or not at all.

The following quotes from the domestic participants illustrate these points: 
"When people came around to talk about careers it was mostly arts."

"I went to a girl's school and they don't come around to talk about engineering, they talk about nursing and teaching."

"By the time a career counsellor started to talk to us about careers, it was too late because we hadn't selected science or math subjects earlier."

"At school, our perception of engineering is trades and workshop, I didn't know engineering was a career until I went to university and studied earth science and learned about engineering indirectly."

"There was no discussion at school about if you don't select these subjects, you cut yourself off from these careers (e.g., science, engineering, etc.) until year 13 when it was too late."

"There was no link between subject choice and careers, it was more about if you don't do well, you don't go to university."

\subsection{Peer Influence}

Neither groups indicated strong peer influence for choosing engineering. No international participants noted peer influence relating to their choice of engineering study. One of the domestic participants said, "A lot depends on what your friends are choosing to do but if you are fairly driven, that's probably not much of a factor."

Two other domestic participants said, "I didn't care what my friends were doing."

\subsection{Media Influence}

The effect of gender stereotypes and media influence was not explored extensively in this research.

\subsection{Self-Efficacy, Perception and Attitude}

Most of our international and domestic participants had a growth mindset, and all identified as being ambitious and hardworking. Domestic participants stated:

"I selected engineering because I am a logical person, and a problem solver and engineering suits me."

One participant who didn't like her brothers' way of life said that "This motivated me to pursue a career because I didn't want to be like them and I wanted to own things (buy a house, etc.)."

"My motivation comes from my mother, she is a manager, and very hardworking, she wanted me to go and study and get a good job."
"[My motivation comes from] seeing my parents working hard and being financially stable, it encourages me to be ambitious and hardworking."

"I am ambitious and hardworking, and my motivation comes from fear of failure, anything I commit to, I give it $120 \%$, for me B is a failure."

\subsection{Society's Perception of Engineers and Lack of Promotion of the Profession}

The international participants observed that in their country, engineering is seen as a prestigious qualification, well-paid, and highly sought-after career. Conversely, New Zealand society's perception of Engineers and the Engineering profession appeared to be a barrier to selection of this career pathway for the domestic participants. For example, one of the participants stated: "People who work in workshops, call themselves engineers, they have lots of grease and lots of girls can get put off by this image of an engineer". The following quotes illustrate the lack of information and visibility of engineers in New Zealand:

"Engineers are unseen, it's not until someone says look at this building, engineers design the foundation, they tested the soils, they did all the structures, and then people start understanding the breadth and scope of engineering."

"As a young girl, when would you ever meet an engineer."

"We need to show people different aspects of engineering like engineers help to build our community or making our road safer, to make the profession more accessible."

The results of this study show in New Zealand, barriers to selection of engineering pathway for females include; the school system, lack of career and subject choice guidance, poor promotion of the profession as a study choice and the perception around the work that engineers do as being masculine. These points will be discussed further in the following section.

\section{DISCUSSION}

The prevailing research relating to female participation in STEM subjects shows the importance of parental influence on study selection particularly mothers' gender related career expectations as noted by Saucerman and Vasquez [21]. This aligns with what we observed from our international participant responses - there was a strong influence from parents in terms of guiding their study and career choices. However, the domestic participants sample group, did not portray strong evidence during discussions that parental influence was a large factor in terms of engineering career selection. The domestic participants received emotional support from their parents in terms of 
study/work after school and their parents responded, "do whatever you want to do".

Most of our domestic and international participants acknowledged that a lot of their selfconfidence came from the encouragement of their parents. Participants confirmed that their view of their own strengths closely resembled their parents view of them. Bleeker and Jacobs [5] also identified that girls' success in STEM, correlated with their mothers' expectations for their success.

The largest barrier for domestic participants, appeared to be the school system and the lack of career guidance. The international participants journey into engineering was more structured and facilitated by their school systems. STEM aptitude was identified early in school and then a defined path into engineering was set for those who showed promise in these areas. While, for domestic participants, career advice was provided typically late and limited to careers such as nursing, teaching, the arts and trades. This led participants to self-select their school subjects with little knowledge of how this would affect their future pathways or career direction. The majority of the domestic participants therefore did not select science and maths at high school, thus limiting their career and study options after school.

Most of the domestic participants went to coeducational schools which contrasts with the study by Docherty et al. [11] that a lower percentage of girls from co-educational school's study engineering. Perry and Bussey [20] suggest, teachers have an unconscious bias that males are better at STEM subjects. Our participants confirmed that they did not receive support/career advice from their teachers, this may be because teachers in coeducational schools are less likely to encourage female students to study engineering or they do not have enough information to advise them on engineering career paths.

Majority of our domestic participants interest or identification of engineering as a career pathway came later in life (they said this was due to a lack of guidance from school or career advisors), after they had either studied or worked in different areas after high school. They found their interest in engineering in more indirect ways, for example, one participant studied Biology and found she particularly enjoyed an earth science elective paper. This eventually led her to pursue engineering after finishing a Science degree.

The unique characteristics of the majority of the domestic focus group participants was that they were all adult learners. Our participants are studying at Wintec which is a polytechnic institution and the way that courses are structured, gives adult learners the flexibility of studying and working at the same time. However, further study is needed to compare different cohorts of students from other polytechnic institutions and also universities to compliment these findings.

Dweck [13] noted the benefits of a growth mindset to academic success, and this theory aligns with our findings. The majority of our domestic and international participants had a growth mindset, and all identified as being "ambitious and hardworking". We believe that if we promote engineering more and in different ways, we may be able to capture a broader range of people and a better cross section of potential female engineering students rather than only allowing the ambitious hardworking students with growth mindsets to find their journey to engineering. Blackwell et al. [4], [12] identified that a growth mindset could be taught, and future educational curriculum could focus on developing this growth mindset in students.

As observed in the study by Atiq [2], the media and the public have long perceived engineering as a masculine area. Our findings partially agree with this study, we observed that New Zealand society's perception of engineers was different from that of our international participants countries. It seems that engineering holds more weight in countries like India and Sri Lanka, and other cultures seem to have more information about what professional engineers do or at least engineering is seen as a prestigious and well-paid occupation. Whereas in New Zealand, the perception of engineers gets mixed up with that of the trades and this public perception (as confirmed by Atiq [2]) presents a barrier to selection of the engineering career pathway for female domestic students.

Findings from our study confirms that, due to the lack of promotion and knowledge of what engineering is about, students rely on media and hearsay to form a perception about engineering, and this perception is that the field is masculine, physical and is more about things rather than people [24].

We believe that the limited promotion of engineering in schools in New Zealand is part of the problem causing the lack of gender diversity at tertiary education. The professional engineering bodies need to work well with schools to promote engineering to students.

Our study identified different ideas relating to the misrepresentation of the profession and how this plays a role in the lack of girls' participation in engineering. The participants from both groups were in agreement that engineering needed to be promoted with more of an emotional connection to people's daily life, communities, the environment and generally a more holistic representation. This correlates with other studies e.g. by $\mathrm{Su}$ et al. [24] that show women are more drawn to people related professions. At the moment, engineering is not well promoted as a profession that improves people's lives. To better promote engineering for girls, we need to present the 
range of possibilities available for working as an engineer such as academic positions, consulting, contracting work, government and show them that you can still be feminine and work as an engineer.

These findings are initial, and we will expand this study to look at other polytechnic institutes across New Zealand and also universities (as they have a different intake of female students i.e. straight from high school) to be able to shine more light onto the lack of gender diversity in engineering at the tertiary education level and engineering as a profession.

\section{ACKNOWLEDGEMENTS}

We would like to thank our wonderful students who participated in this research. We also would like to acknowledge the support we received from the Centre for Engineering and Industrial Design at Wintec.

\section{REFERENCES}

1. Andre, T., M. Whigham, A. Hendrickson, and S. Chambers, Competency beliefs, positive affect, and gender stereotypes of elementary students and their parents about science versus other school subjects. Journal of Research in Science Teaching, 1999. 36(6): p. 719-747.

2. Atiq, Z. Women's Motivation to Pursue Engineering Careers in Academia versus Industry : A Case Study of Malaysia. 2018.

3. Beede, D., T. Julian, D. Langdon, G. McKittrick, B. Khan, and M. Doms, Women in STEM: A gender gap to innovation. SSRN Electronic Journal, 2011.

4. Blackwell, L.S., K.H. Trzesniewski, and C.S. Dweck, Implicit Theories of Intelligence Predict Achievement Across an Adolescent Transition: A Longitudinal Study and an Intervention. Child Development, 2007. 78(1): p. 246-263.

5. Bleeker, M. and J. Jacobs, Achievement in Math and Science: Do Mothers' Beliefs Matter 12 Years Later? Journal of Educational Psychology, 2004. 96: p. 97109.

6. Chhin, C.S., M.M. Bleeker, and J.E. Jacobs, Gendertyped occupational choices: The long-term impact of parents' beliefs and expectations, in Gender and occupational outcomes: Longitudinal assessments of individual, social, and cultural influences. 2008, American Psychological Association: Washington, DC, US. p. 215-234.

7. Cohen, L., L. Manion, and K. Morrison, Research methods in education. 2018.

8. Crowley, K., M.A. Callanan, H.R. Tenenbaum, and E Allen, Parents Explain More Often to Boys Than to Girls During Shared Scientific Thinking.

Psychological Science, 2001. 12(3): p. 258-261.

9. Devine, P.G., Stereotypes and prejudice: Their automatic and controlled components. Journal of Personality and Social Psychology, 1989. 56(1): p. 518.

10. Dickhäuser, O. and W.-U. Meyer, Gender differences in young children's math ability attributions.

Psychology Science, 2006. 48.
11. Docherty, P.D., J. Chase, W.H. Fox, K.a. Naswell, and P. Williamson. Where do New Zealand female engineers come from? Insights from a quantitative analysis. in 29th Australasian Association for Engineering Education Conference 2018 (AAEE 2018). 2018. Hamilton, New Zealand: Engineers Australia, 2018: 781-786.

12. Dweck, C., Mindset changing the way you think to fulfil your potential. 2017.

13. Dweck, C.S., Is Math a Gift? Beliefs That Put Females at Risk, in Why aren't more women in science?: Top researchers debate the evidence. 2007, American Psychological Association: Washington, DC, US. p. 47-55.

14. Huyer, S., Is the Gender Gap Narrowing in Science and Engineering? 2018.

15. Kenney-Benson, G.A., E.M. Pomerantz, A.M. Ryan, and H. Patrick, Sex differences in math performance: The role of children's approach to schoolwork. Developmental Psychology, 2006. 42(1): p. 11-26.

16. Levine, S.C., L.W. Suriyakham, M.L. Rowe, J. Huttenlocher, and E.A. Gunderson, What counts in the development of young children's number knowledge? Developmental Psychology, 2010. 46(5): p. 13091319.

17. Mozahem, N.A., C.M. Ghanem, F.K. Hamieh, and R.E. Shoujaa, Women in engineering: A qualitative investigation of the contextual support and barriers to their career choice. Women's Studies International Forum, 2019. 74: p. 127-136.

18. Muzzatti, B. and F. Agnoli, Gender and mathematics: Attitudes and stereotype threat susceptibility in Italian children. Developmental Psychology, 2007. 43(3): p. 747-759.

19. Neuman, W.L., Social research methods : qualitative and quantitative approaches. 2011, Boston: Allyn \& Bacon.

20. Perry, D.G. and K. Bussey, The social learning theory of sex differences: Imitation is alive and well. Journal of Personality and Social Psychology, 1979. 37(10): p. 1699-1712.

21. Saucerman, J. and K. Vasquez, Psychological barriers to STEM participation for women over the course of development. Adultspan Journal, 2014. 13(1): p. 4664.

22. Stake, J.E., The Critical Mediating Role of Social Encouragement for Science Motivation and Confidence Among High School Girls and Boysl. Journal of Applied Social Psychology, 2006. 36(4): p. 1017-1045.

23. Stake, J.E. and S.D. Nickens, Adolescent Girls' and Boys' Science Peer Relationships and Perceptions of the Possible Self as Scientist. Sex Roles, 2005. 52(1): p. 1-11.

24. Su, R., J. Rounds, and P. Armstrong, Men and Things Women and People: A Meta-Analysis of Sex Differences in Interests. Psychological bulletin, 2009. 135: p. 859-84.

25. Talton, E.L. and R.D. Simpson, Relationships between peer and individual attitudes toward science among adolescent students. Science Education, 1985. 69(1): p. 19-24.

26. Tiedemann, J., Parents' gender stereotypes and teachers' beliefs as predictors of children's concept of their mathematical ability in elementary school. Journal of Educational Psychology, 2000. 92(1): p. 144-151. 